\title{
Indígenas em contexto urbano, conflitos socioculturais e linguísticos: o exemplo dos Akwẽ-Xerente
}

\author{
Indians in urban context, socio-cultural and linguistic conflicts: The \\ example of Akwe-Xerente
}

http://dx.doi.org/10.5007/2178-4582.2015v49n2p143

Rodrigo Mesquita

Universidade Federal de Roraima, Boa Vista, RR, Brasil

\begin{abstract}
Neste trabalho são discutidos, sob a perspectiva da sociolinguística, aspectos da ocupação Xerente no município de Tocantínia, pequena cidade situada cem quilômetros ao norte de Palmas (TO) e dentro da qual se encontra a maior parte das terras indígenas Xerente e Funil. O método etnográfico orientou a coleta dos dados e a observação da realidade sociolinguística do povo Akwẽ-Xerente na cidade. Dentre outros aspectos, são apresentados os pontos de conflitos socioculturais em contexto urbano, dadas a realidade de migração constante e a situação de marginalização a que os indígenas são expostos em tal ambiente. Através da observação de fenômenos de contato, tais como empréstimos linguísticos e code-switching (alternância de línguas) verificou-se que os eventos de fala realizados na (ou sobre a) cidade são os que apresentam maior frequência e diversidade/complexidade, revelando assim o ambiente urbano como uma zona potencializadora de conflitos diversos para os indígenas, como é o caso dos Xerente.
\end{abstract}

Palavras-chave: Indígenas em contexto urbano; Sociolinguística; Fenômenos de contato; Code-switching.
In this paper, and from the standpoint of sociolinguistics, we discuss some aspects of the Xerente occupation in the municipality of Tocantinia, a small city located north of Palmas (TO). The ethnographic method served as a guide for data collection and for the observation of the sociolinguistic reality of the Akwe-Xerente people in the city. Among other aspects, the paper presents the points of sociocultural conflicts within the urban context, given the constant migration process that takes place and the marginalized situation in which these indigenous populations are exposed in such an environment. Through the observation of contact phenomena, such as loanwords and code-switching (alternating languages), it was found that the speech events held in (or on) the city are those with greater frequency and diversity / complexity, revealing the urban environment as a potentiating area of several conflicts for indigenous peoples, as is the case of the Xerente.

Keywords: Urban indigenous populations; Sociolinguistics; Contact phenomena; Code-switching.

\section{Introdução}

As ocupações urbanas, tema central desta edição, geralmente espelham um ideal civilizatório no qual há uma oposição determinante em relação às populações rurais ou que habitam outros espaços que não a cidade. Fruto de uma herança histórica baseada na hegemonia da cultura ocidental, a imagem estereotipada do indígena se confunde com a do habitante de terras longínquas e isoladas e que "não combina" com o ambiente urbano. 
A desinformação sobre o assunto, aliada à falta de políticas públicas (ou de sua implementação) voltadas para a valorização da diversidade, seja cultural, de organização social e linguística no território nacional ajuda a disseminar afirmações de senso comum que insistem em reduzir os povos indígenas a uma classe geral. Assim, não é difícil encontrar pessoas que acreditam que eles se comportam da mesma maneira, falam todos uma mesma língua, acreditam nas mesmas coisas e ocupam um mesmo espaço: as aldeias. Qualquer comportamento diferente disso é interpretado como aculturação, ou seja, índios que saíram de suas aldeias, que utilizam tecnologias e/ou produtos industrializados dos não-índios, já não seriam mais índios.

A realidade, porém, indica algo muito diferente. Dados do IBGE de 2010, o último censo da população indígena realizado até então, apontam um total de 896,9 mil pessoas que se declararam $(817,9$ mil) ou se consideraram indígenas (78,9 mil). Do total, mais de 315 mil pessoas viviam na cidade, número menor do que o registrado no ano 2000 (383,3 mil), mas ainda bastante expressivo. No entanto, o número de municípios brasileiros que possuem habitantes indígenas vivendo em área urbana vem crescendo continuamente. Em 2000, mais da metade dos municípios brasileiros $(50,7 \%)$ tinham indígenas habitando seus centros urbanos, número que chegou a $72,4 \%$ em 2010. A maior parte dessa população indígena nas cidades é composta por jovens de até 24 anos que migram de suas aldeias por motivos/objetivos diversos.

Os dados do IBGE (2010) também identificaram 305 etnias e 274 línguas. Todos esses números são questionáveis, seja quanto aos seus métodos de obtenção e/ou outras interpretações de natureza teórica. Isso já fora feito por especialistas nas áreas específicas ao longo dos últimos anos. Não é nosso foco aprofundar esta discussão. De qualquer forma, chama a atenção a diversidade sociocultural e linguística das populações, assim como a forma como estão distribuídas pelo território brasileiro. Nesse sentido, concordamos com Rosado e Fagundes quando afirmam que:

[...] uma vez residindo na cidade, os indígenas redefinem o processo de territorialidade, manifesto ora pelos conflitos sociambientais, ora pelos vínculos estabelecidos com as áreas, que se apresentam como espaços de relações sociocosmológicas. A partir desses espaços processam a renovação do compromisso com o passado e reelaboram suas culturas, diante dos contextos interculturais ao qual se encontram imersos. Desta forma produzem inúmeras formas associativas, reunindo raízes locais, laços de solidariedade, autodefinições coletivas, consciência ambiental e singularidades culturais (ROSADO; FAGUNDES, 2013, p.8). 
As diversas situações e configurações do contato dos povos indígenas com a cultura (geralmente) dominante, que muitas vezes se impõe apresentam marcas que podem emergir através de atitudes, comportamentos culturais e, como propomos analisar neste trabalho, comportamentos linguísticos.

O objetivo do presente artigo é refletir sobre os espaços urbanos com a presença de populações indígenas e os decorrentes conflitos socioculturais e linguísticos decorrentes dessas realidades. O foco especial é colocado sobre o caso dos Xerente de Tocantínia (TO) e os fenômenos de contato que permeiam os usos linguísticos daquele povo.

Este estudo é parte integrante de uma pesquisa de natureza sociolinguística, corrente teórica de abrangência interdisciplinar. Assim, a sociolinguística inclui fontes de distintas pesquisas cientificamente orientadas, entre elas a etnografia da comunicação, a sociologia da linguagem e a psicologia social. A seguir, apresentamos nosso recorte teórico, assim como os métodos adotados na coleta e apresentação dos dados.

\section{Orientações teóricas e métodos}

A realização da pesquisa (MESQUITA, 2015) da qual deriva este artigo, parte da intenção de diagnosticar, na comunidade indígena Akwẽ, os campos propensos a conflitos relacionados à distribuição dos papéis ou funções sociais da língua xerente e portuguesa, ou seja, diglossia, a partir do uso de empréstimos e, especialmente, do code-switching (doravante CS), um dos fenômenos oriundos do contato linguístico. O CS consiste, basicamente, na alternância entre línguas, entre falantes bilíngues, em uma mesma situação comunicativa (GROSJEAN, 1982).

Para observação dos fenômenos linguísticos nos servimos dos pressupostos da Etnografia da Comunicação (HYMES, 1972 [1964], 1974 e 1986). Hymes (1972), em texto originalmente publicado em 1964 na revista American Anthropologist, propõe um modelo multidisciplinar de investigação do comportamento comunicativo em contextos culturais, a Etnografia da Fala ou Etnografia da Comunicação. De forma geral, a etnografia da comunicação examina as perspectivas teóricas para o estudo da comunicação em diferentes contextos culturais. Entre os tópicos, podem estar padrões interculturais e intraculturais de comunicação, o efeito das diferenças culturais sobre as interações, os conceitos de cultura, comportamento não-verbal e, ainda, de eficácia intercultural.

Para demonstrar a importância da ocupação do ambiente urbano na (re) elaboração sociocultural e linguística do povo Xerente, analisamos dados 
coletados' desde 2011 (gravados em áudio, vídeo e/ou registro em diário de campo) com foco especial sobre fenômenos de contato identificados no comportamento linguístico dos indígenas.

Tais fenômenos, em algumas de suas formas, são possíveis somente em situação de bilinguismo alto (BRAGGIO, 2010), em que os falantes possuem proficiência nas duas línguas - no caso, xerente e portuguesa. Apesar de serem fenômenos comuns em contextos bilíngues, a forma como eles se dão pode ser reveladora de aspectos da realidade sociocultural de uma comunidade de fala. Conforme Hymes (1972) e Gumperz (1996), esse conceito remete a um conjunto de redes de socialização associados a padrões linguísticos de uso e interpretação. Dessa forma, os significados estão associados a práticas interpretativas que, por sua vez, se localizam em redes sociais.

Hymes (1986) define ainda o evento de fala como um momento em que dois ou mais falantes se comunicam, em ocasiões de atividades ou aspectos de atividades sociais que são diretamente governadas por regras ou normas para o uso da fala, definidas na comunidade de fala. Neste sentido, o autor considera a comunidade de fala como unidade natural da teoria sociolinguística, por ser caracterizada como um todo organizado por normas compartilhadas que regulam as diferentes situações e eventos comunicativos e que compartilha a mesma concepção social e cultural do mundo. Neste artigo, a atenção especial está voltada para os eventos de fala que ocorrem na cidade e, oportunamente, realiza-se comparações com outros eventos.

A faixa etária dos falantes também é uma variável determinante para a observação de fenômenos linguísticos. As faixas etárias consideradas foram, portanto, a) +jovens (12 a 20 anos); b) \pm jovens (21 a 49 anos) e c) +velhos (50 anos ou mais). As transcrições seguem as ortografias propostas para a língua xerente (KRIEGER; KRIEGER, 1994) e a ortografia padrão da língua portuguesa, com máxima aproximação à produção fônica real.

Dentro da perspectiva sociolinguística, os estudos podem focar situações de bilinguismo estável (sem diglossia) ou bilinguismo diglóssico (HAMEL,

Os dados foram coletados nas aldeias e na cidade com a utilização do método etnográfico, privilegiando os eventos de fala natural em situações de interação o mais naturais possíveis. Isso significa que não houve qualquer tentativa de manipulação dos contextos em que os dados foram registrados. Foram realizadas, para tanto, sete viagens a campo entre 2011 e 2014. No entanto, nosso trabalho com os xerente se dá desde 2005, o que nos permitiu uma visão mais diacrônica de sua realidade.

\footnotetext{
A divisão de faixas etárias segue a divisão proposta por Braggio (2005b), que justifica ser adequada à própria organização sociocultural xerente e representativa de quatro gerações. A primeira delas, ou seja, composta pelas crianças menores de doze anos não foi considerada para efeito de análise neste trabalho. Para mais detalhes, ver Braggio (2005b).
} 
1988; ROMAINE, 1995; BRAGGIO 2001/2002). Mesmo o chamado "bilinguismo estável”, situação em que duas línguas ou variedades coexistiriam de forma harmoniosa, como explica Cáccamo (1987, p.132), "está fundamentado, em numerosas ocasiões, na estratificação social, e sua função é a de bloquear a mobilidade entre estratos sociais".

Essa noção de repartição harmoniosa quanto à distribuição das funções sociais das línguas foi, inclusive, a que motivou Ferguson (1972 [1959]) a elaborar o primeiro conceito de diglossia. Esse conceito foi, alguns anos mais tarde, revisitado por Fishman (1967), porém de forma ampliada e com uma nova delimitação teórica. É ampliada quando abarca toda e qualquer situação marcada por distribuição funcional socialmente determinada na comunidade de fala, incluindo situações assimétricas entre línguas ou variantes. Isso significa que, em comunidades bilíngues, uma língua pode ter mais funções sociais que outra ou ter funções mais abrangentes e valorizadas socialmente, tal é o caso dos Xerente, como veremos mais adiante. Ainda segundo Fishman (1967), as noções de bilinguismo e diglossia caberiam, respectivamente, ao nível individual e social.

Também contribuiu para a reelaboração do conceito de diglossia os estudos realizados nos anos seguintes por linguistas que se dedicaram a estudar sua própria realidade. Como observa Calvet (2007), o surgimento de uma sociolinguística "nativa" lançou um novo olhar sobre os contextos de contato linguístico. $\mathrm{O}$ termo utilizado pelo autor diz respeito a estudos realizados "pelos linguistas nativos, ou seja, aqueles oriundos de situações diglóssicas" (CALVET, 2007, p.33). Vista por outro ângulo, estes linguistas

[..] afirmavam que a diglossia não era uma coexistência harmoniosa entre duas variedades linguísticas, mas uma situação conflituosa entre uma língua dominante e uma língua dominada. Ora, de acordo com Lluis $\mathrm{Aracil}^{3}$, esse conflito só poderia levar a duas situações: ou a língua dominada desaparece em favor da língua dominante (o que ele chama de substituição), ou ela recupera suas funções e seus direitos (o que ele chama de normalização) (CALVET, 2007, p.33-34, grifo do autor).

É nesse sentido que Braggio (2001; 2002) aponta a diglossia como uma das principais razões que têm levado as línguas indígenas à morte, uma vez que pode levar ao deslocamento da língua de menor prestígio. A autora explica que uma comunidade indígena pode passar (de geração a geração) de monolíngue na língua materna à bilíngue, incluindo a língua de contato em

\footnotetext{
O texto citado por Calvet (2007) é do catalão Lluis Aracil, Conflict linguistic i normalitzacio linguística a l'Europa nova, 1965 (versão francesa, mimeo) e 1982 (versão catalã). Outros estudos da mesma natureza citados são os Lafont (1971) e Prudent (1981).
} 
seu repertório, até um estágio final em que se torna monolíngue nesta última, levando a língua indígena à extinção. Uma vez que esse processo se dá lentamente, não é facilmente perceptível. Nesse sentido, a alta frequência no uso de code-switching e a forma como ele se dá, além da adoção de inúmeros empréstimos linguísticos, pode ser um índice de um conflito diglóssico mais profundamente arraigado.

Além da diglossia, a autora também aponta outros fatores que têm levado as línguas à extinção, a saber: i) o processo de colonização do Brasil; ii) as políticas com relação a esses povos e suas línguas; iii) a globalização; iv) as mudanças estruturais e funcionais das línguas através dos empréstimos massivos lexicais e gramaticais e das correntes alternâncias de línguas intra e interpessoais, por regras sociolinguísticas conflituosas e da perda de suas funções nos mais diferentes domínios sociais e de gêneros e estilos discursivos; e v) as atitudes dos falantes com relação às próprias línguas. Com essa preocupação, Braggio (2005a) aponta também a questão da migração como um possível fator negativo no processo de deslocamento das línguas indígenas, seja ocasionando um comportamento diferenciado no que diz respeito à atitude linguística de seus falantes, seja com interferências pela língua oficial na própria estrutura das línguas.

No caso específico dos Xerente, uma análise de frequência (MESQUITA, 2009) identificou uma maior intensidade no uso de empréstimos linguísticos no ambiente urbano (e também que eram mais frequentes entre os mais jovens e mais escolarizados). Esse estudo também verificou que alguns tópicos/ assuntos eram potencializadores para a ocorrência do fenômeno, tais como programas de televisão, problemas burocráticos (geralmente resolvidos na cidade), novidades tecnológicas, assuntos escolares, entre outros, ainda mais comuns no contexto citadino. O mesmo se verificou em relação ao code-switching, como veremos nas análises mais adiante.

Na cidade, há ainda outras pressões que podem estar em atuação. Cáccamo, baseado em Fishman (1985) lembra que:

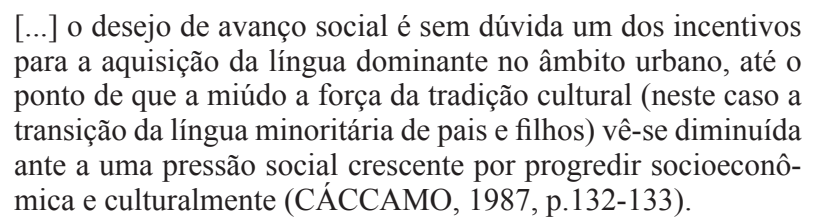

Outro conflito diglóssico se dá no campo da transmissão do conhecimento e/ou da educação escolar. Grosjean (1982), por exemplo, considera que a língua prestigiada geralmente está associada a modelos de desenvolvimento, 
progresso e mercado de trabalho, o que pode implicar diretamente em atitudes negativas por parte dos falantes das línguas minorizadas. Há uma série de conflitos envolvendo a educação escolar indígena ${ }^{4}$, que vão desde a atitude dos pais, que divergem quanto à língua em que seus filhos deverão ser educados (xerente ou português), até as políticas públicas que estão longe de efetivar o que está garantido no papel, ou seja, uma educação diferenciada, dentro dos moldes e necessidades da cultura.

Vários estudos realizados após as publicações de Ferguson (1959) e Fishman (1967) mostraram uma diversidade de configurações de distribuições funcionais entre as línguas envolvidas e muitos deles questionaram a categorização inicialmente proposta. Isso levou Ferguson (1991, p.225) a responder que "minha formulação original de diglossia não tinha a intenção de conter todos os exemplos de multilinguíssimo ou diferenciação funcional das línguas". No mesmo texto, o autor reconhece uma série de fragilidades da explanação original, tal como alguns conceitos empregados (de variedade e distância linguística, por exemplo), a falta de descrição dos casos de diglossia dentro de contextos maiores (incluindo efeitos das diferenças de poder político, econômico e cultural) e a clarificação da importância da força diferencial na escolha das variedades.

\section{Aspectos da realidade Xerente: dos primeiros contatos à ocupação urbana}

O povo indígena Akwẽ-Xerente tem uma população estimada em 3,6 mil indivíduos. A maior parte dessa população está distribuída entre as mais de 60 aldeias espalhadas pelas áreas indígenas Xerente e Funil, demarcadas em 1972 e 1988, respectivamente. As duas áreas encontram-se contíguas ao centro urbano de Tocantínia, que está situado em posição central. Assim, para deslocar-se de uma área a outra é necessário passar pela cidade. Da mesma forma, o acesso de Tocantínia para outras cidades se dá por vias que cortam as áreas indígenas, o que frequentemente causa desavenças entre indígenas e não-indígenas. Recentemente (final de 2014), uma ponte dentro da área indígena Xerente foi destruída. Índios e não-índios se acusaram e todos ficaram prejudicados.

Outra parte da população, estimada em cerca de 10\% (MESQUITA, 2009, 2015), vive em Tocantínia, município situado à margem direita do rio Tocantins, aproximadamente cem quilômetros ao norte de Palmas, capital do estado do Tocantins. 
Em 2005, data de nosso primeiro contato com os Xerente, eram aproximadamente trezentos indígenas vivendo na cidade, número que pode ter aumentado nos últimos anos. No levantamento realizado naquele período (MESQUITA, 2006), somavam em torno de 50 famílias distribuídas em aproximadamente 30 casas - há casas com mais de uma família - que se dispõem espalhadas em várias partes da cidade. Notamos, entretanto, a formação de pequenos aglomeramentos de 5 ou 6 casas em regiões mais periféricas da cidade, o que demonstra a intenção de viverem mais próximos uns dos outros, como assinala um de nossos auxiliares de pesquisa, Bonfim Xerente: "nós Xerente, nós queremos viver assim, mais próximo um do outro”. Porém, completa Bonfim: "o problema é que não tem como conseguir de ser próximo, por causa do aluguel...”.

Na cidade, é possível observar a movimentação dos Xerente diariamente e em vários espaços, principalmente na praça central, que funciona como ponto de encontro para os indígenas e onde também funciona um feira de artesanatos semanal. Também é possível observar (mesmo sem um olhar sistemático sobre tal realidade) que muitos indígenas são discriminados e expostos ao uso abusivo de álcool, colocados assim à margem da sociedade. Em várias situações, testemunhamos indígenas sendo ofendidos no comércio, no transporte coletivo e em demais locais públicos, muitas vezes sem qualquer motivo aparente.

O processo de migração para a cidade, como temos verificado (MESQUITA, 2006; 2015), é crescente e tem ocorrido tanto entre jovens como adultos. Os primeiros, influenciados muitas vezes pelos próprios pais, partem para a cidade para que possam continuar ou começar os estudos, ou por considerarem as escolas melhores que as das aldeias. Consequentemente, pais e parentes acompanham os filhos e se submetem a dificuldades diversas num contexto de conflito interétnico, de assimetria política e econômica. Em 2006, havia aproximadamente cento e cinquenta crianças e jovens Xerente matriculados nas escolas da cidade. Em 2012, havia cento e oitenta e dois alunos matriculados, mesmo com vagas de educação infantil e ensino fundamental nas escolas distribuídas dentro da reserva Xerente. Outro fator apontado pelos Xerente para a migração são os problemas com relação ao atendimento adequado de saúde nas suas aldeias, o que os leva à busca-lo na cidade, mesmo com as condições desfavoráveis a que se submetem.

Da mesma forma, a língua nativa também se encontra em posição desfavorável em relação ao português, dada a assimetria da distribuição das funções sociais exercidas pelas línguas. Enquanto que nas aldeias a língua indígena é amplamente utilizada nas tarefas cotidianas, na cidade o português é a língua predominante no comércio, na escola, nas repartições públicas, etc., 
ficando a língua Xerente restrita à comunicação entre os próprios indígenas. Isso caracteriza um conflito diglóssico, tal qual discutimos na seção anterior.

Tal situação sociolinguística é reflexo de um processo histórico que se iniciou, conforme Farias (1990), no século XVII. O período entre 1749 e 1811 marca a chegada de grandes contingentes populacionais à então Capitania de Goyaz. Isso se deu após os avanços de bandeirantes (sertanistas do Brasil colonial) que encontraram na região do Brasil central terras propícias para a exploração vegetal e mineral, além de áreas para pastagem.

Documentos do século XIX demonstram que os Xerente, além de outros povos indígenas, foram duramente perseguidos e tratados como entrave aos planos do governo, como temos no trecho a seguir, no qual o então governador da Província de Goyaz, Luiz Gonzaga de Camargo Fleury, relata os desfechos de um dos muitos confrontos:

\begin{abstract}
[...] ordenou (o dito chefe Xuaté) ao Pelotão que mortos todos os nossos rezervasse dous, que amarrados lhe deveriao ser condusidos; aterrados porem os que formavao o Pelotão pela nossa Cavallaria, correrão em debandada, e avisando a Aldeia, foi esta instantaneamente abandonada, por quanto ao pôr do Sol, entrando a nossa Força a ninguém encontrou; no dia seguinte se divisava o Cherente em grupos pelos picos da Montanha, que serve como de Fortaleza a Aldeã, e em altas vozes pedirão a paz, e contra o voto de Abulquerque que desconfiava com rasao da sinceridade d'huma Nação, reconhecida por falsa, começarão se os ajustes; desceo huma parte, e por machados, e fouces entregarão seis Christãos, que tinhao presioneiros, constando por estes existir mais dez ainda em tão desgraçado estado; os quaes não se poderão resgatar, porque no dia seguinte, appareceo o Cherente de repente sobre a montanha, e declarando que nada queriao em paz, levantarão o grito de guerra; toma a nossa gente as Armas, procura subir a Montanha, mas não foi possível haver ação alguma; e o Cherente embrenhou-se pelas matas, e serranias de tal sorte que não poude mais ser visto pelos nossos: conheceo se então que a paz pedida foi hum estrategema para dar tempo as mulheres, meninos e velhos a se porem a salvo (FLEURY, 1835, apud MORAIS NETO, 2007, p.36-37).
\end{abstract}

Nesse contexto, eram comuns os relatos de sequestros de crianças não indígenas e saques às fazendas por parte dos indígenas, assim como sequestros de crianças e mulheres Xerente, além da aniquilação de lavouras e aldeias inteiras, por parte das tropas provincianas. Ataques eram realizados pelas duas partes, seguramente por motivos diferentes. De um lado, as tropas da província e a população sertaneja, apoiada pelo governo, avançaram em busca de terras para pastagem e exploração vegetal e mineral. De outro lado, os Xerente travaram diversas batalhas por sua sobrevivência. 
Giraldin e Silva (2002) dividem a história da relação Xerente/não-indígena do médio Tocantins durante o século XIX em duas fases. A primeira vai da publicação da Carta Régia de 05 de setembro de 1811 até o aldeamento de Tereza Cristina, em 1851, e é marcada pelo desejo do povo Xerente de preservar seu território, sua caça, sua gente. Nesse período,

[...] a cada agressão do não-índio aos xerente, constitui-se revide destes com uma ação de guerra. A cada invasão de seu mundo, eles se apresentam de arma na mão lutando com técnica e inteligência. No entanto, quando lhes convêm, apresentamse como hábeis negociadores, acertam termos de paz, ganham tempo, organizam-se, convivem pacificamente; agredidos, acabam atacando novamente (GIRALDIN E SILVA, 2002, p.15).

A segunda fase relatada pelos autores começa com o aldeamento Tereza Cristina indo até o final do século XIX. Essa é a fase do aldeamento, e tem como marca uma crescente assimilação de cultura circundante e um decréscimo populacional. A assimilação da cultura alheia é caracterizada pela influência da religião católica, da língua portuguesa (através das escolas de primeiras letras) e pelo trabalho "branco". Para Giraldin e Silva:

\footnotetext{
[...] se na primeira metade do século, os xerente são guerreiros altivos laboriosos que defendem a sua não-assimilação, na segunda metade estes parecem estar vencidos e que vão sendo dizimados, não pela força das armas, da qual souberam se defender. Ao contrário de outras nações aniquiladas na região goiana, os xerente absorvem ativamente a cultura circundante, mas sobrevivem (física e culturalmente) (2002, p.15).
}

Foi justamente o aldeamento Tereza Cristina (ou Piabanhas), sob a responsabilidade do frei Raphael de Taggia e, mais tarde (por volta de 1870), do frei Antônio de Ganges, que cedeu lugar à atual zona urbana do município de Tocantínia. Isso significa que a atual migração para a cidade por parte dos Xerente, na verdade, representa uma espécie de retorno a um território outrora ocupado por seus ancestrais.

Na visão de Silva, a partir da Proclamação da República (em 1889), a política indigenista implantada "deixa livre o caminho para novas investidas sobre os xerente e o que deles possa interessar" (2006, p.99), uma vez que "estará aberto por definitivo o campo para pressões de forças econômicas, sociais e políticas locais que buscaram ansiosas auferir das vantagens que o momento lhes propiciava". (Ibid.).

Durante todo esse período, a demografia sofreu um decréscimo que quase levou os Xerente à extinção. Ribeiro (1986) contabilizou apenas tre- 
zentos e cinquenta indivíduos em 1957. A recuperação demográfica só foi possível a partir da demarcação das terras indígenas Xerente (em 1972) e Funil (em 1988) com as garantias advindas da Constituição Federal de 1988. A população atual, como dissemos, é estimada em torno de 3.600 indivíduos.

Mas, atualmente, um fato pode ser considerado marcante para a ampliação do fluxo de deslocamento para cidade. Em 2001 foi inaugurada a usina hidrelétrica Luís Eduardo Magalhães - Lageado, no rio Tocantins, entre os municípios de Lageado e Miracema do Tocantins. Embora a usina tenha sido construída a quinze quilômetros da terra indígena, o curso do rio Tocantins sofreu alterações, impactando diretamente nas atividades de pesca e irrigação, entre outras mais específicas, desenvolvidas pelos Xerente. Nesse caso, a legislação específica prevê ações compensatórias e programas de mitigação dos impactos junto à população envolvida. Assim, foi criado, em 2002, o Programa de Compensação Ambiental Xerente (PROCAMBIX), fruto de um convênio firmado entre a INVESTCO S/A e a Fundação Nacional do Índio (FUNAI), com interveniência do Ministério Público Federal. O projeto duraria oito anos, com um total aprovado de 10 milhões de reais.

Com a entrada de capital proveniente do PROCAMBIX s, várias associações indígenas foram fundadas para administração da verba destinada aos projetos que deveriam ser realizados em todas as aldeias. As sedes das associações, no entanto, eram instaladas sempre na cidade. Além desse fato, que fortaleceu os Xerente enquanto sujeitos no ambiente urbano, a disponibilidade de recursos financeiros estreitou os laços com a cidade em relação à busca por diversos insumos industrializados aos quais não tinham fácil acesso anteriormente.

Uma importante política recente (de 2012) foi a co-oficialização da língua xerente no município de Tocantínia, resultado de um projeto apresentado por dois vereadores Xerente. Apesar de haver controvérsias entre os próprios Xerente sobre as consequências dessa política linguística, o benefício iminente, em nosso entendimento, é a possibilidade de fortalecimento do status da língua, o que pode refletir diretamente sobre a autoestima dos falantes e ajudar a frear o processo acelerado de invasão da língua indígena pelo português. $\mathrm{O}$ projeto, que se justifica pelo atendimento bilíngue nos serviços básicos do município, como saúde e educação, ainda não resultou, até então, em nada de concreto neste sentido.

O code-switching, ou alternância de códigos, é um dos fenômenos de contato que podem ser relacionados a esse contexto complexo, como mostra a análise em seguida. 


\section{Resultados}

O code-switching nos eventos realizados em ambiente urbano, como se pode observar no exemplo (1) ${ }^{6}$, é frequente e diversificado. Para isso, contribuem uma série de fatores, entre os quais destacamos as características do(s) ambiente(s), os participantes dos eventos e os tópicos dos atos de fala, sem deixar de levar em conta as estratégias interpessoais expressas pelo CS, através da marcação (ou não) dos códigos linguísticos.

No exemplo a seguir, há dois Xerente do sexo masculino, sendo um \pm jovem e um +jovem, além do pesquisador. No evento, realizado na cidade, o falante \pm jovem (que frequenta assiduamente a cidade e que voltaria para aldeia no dia seguinte) dá conselhos e orientações ao outro, seu sobrinho, que passaria a viver ali a partir de então. O exemplo retrata uma situação recorrente entre os Akwẽ, ou seja, a ida para a cidade de jovens indígenas para estudar e/ ou "realizar sonhos":

(1) $X_{1}$ - bâkâ za(hã) hâre aipâ ittkrewanã... tô dapkẽ zedi mais... tem qui sê nõkwa pkẽ(ze) tete.

'E já vou voltar amanhã... e... a saudade dói mas... tem que segurar'.

$\mathrm{X}_{2}$ - dapkẽ tak tete, nõkwa sĩm futuro ku mõr wa, i... aipkẽze knã to (aisĩm) naitê si kmãdâkâ aisĩm sonho, estudo... porque dapkẽze nemãr tê kâ kõdi.

'Saudade a gente segura, quem vai em busca do futuro (melhor), e... não sinta saudade, só olhe para o seu sonho, estudo... porque saudade atrapalha (lit.: 'saudade não pega nada')'.

$\mathrm{X}_{3}$ - bâkã zatô akwẽtmẽzusi... akwẽ, não é só akwẽ! ktâwanõ invejoso. akwẽ invejoso. intão tanẽ (h)ã wapar knã.

'Os akwẽ vão falar... akwẽ, (e) não é só akwẽ! O branco é invejoso. O akwẽ é invejoso. Então não dê ouvidos'.

$\mathrm{X}_{4}$ - pra qui amanhã depois, hâre nõkwai mã waskuda. kanẽ "fui atrás foi do meu sonho, hoje eu realizei". tôka nmãzi kmãnãzei wa. capais di ture kmãnãrdã. intão nada é impossí-

Para facilitar a visualização dos dados, as inserções em português estão em negrito nos exemplos. 
vel nõkwa mãri tê kmãnãda.

'Para que amanhã depois, amanhã conte para alguém. Assim: "fui atrás foi do meu sonho, hoje realizei". Você um dia vai fazer. É capaz de fazer. Então nada é impossível para alguém fazer alguma coisa'.

$\mathrm{X}_{5}$ - bâka, (za) aiptokwai mã hatô isimãsaipês hatõ nẽsi we am ligá. kraimõr pêsê, mãrĩ ktâwanõ sikarĩ sikar nmĩ watkâ tam frêcê wa kâr, knã abas. "não amigo!" kanẽ: "ĩprekõdi mais eu agradeço. eu quero que...ît kme zas nã... eu quero sê seu amigo. não quero ser seu inimigo". nõkwa stôkra.

'Olha, vou falar bem para seu pais e vou continuar ligando. Anda bem, se um branco te oferecer um cigarro que embebeda (droga), não pega. "Não amigo!", assim: "Eu não fumo mas eu agradeço. Eu quero que... eu quero ser seu amigo". Não quero ser seu inimigo". Engana'.

$\mathrm{X}_{6}$ - intão... mãrĩsda wap we tôkumã? aisĩm sonho realiza-dá, i amanhã pra qui você pode mostrá pa cada um aisĩm akwẽmã... aidekwaimã... i realiza-dá.

'Então... para que estou te colocando aqui? Para o seu sonho se realizar, e amanhã, para que você possa mostrar para cada um do seu povo... para sua família... e para realizar'.

No exemplo, há forte incidência de code-switching durante todo o evento de fala. Observa-se que as estratégias discursivas e escolhas linguísticas dos falantes refletem as expectativas sócio-psicológicas relacionadas ao uso de determinado código, ou seja, reflete o conjunto de comportamentos e atitudes normativas estabelecidas e mantidas pela comunidade de fala (MYERS-SCOTTON, 1993). Nesse sentindo, quando dois Xerente se encontram em um mesmo evento de fala, o uso da língua indígena entre eles indica a escolha mais frequente, mais geral ou mais neutra. Não é o que acontece no exemplo e na maioria dos eventos realizados no contexto urbano. Nesse ambiente, o português tende a ocupar espaços normalmente preenchidos pela língua indígena, o que configura um conflito diglóssico que pode ser percebido pela alta frequência no uso de CS e empréstimos.

Os tópicos abordados na cidade têm maior incidência de assuntos relativos a tal ambiente, tais como negócios, processos burocráticos, política, acontecimentos na própria cidade envolvendo indígenas e/ou não-indígenas, etc. $\mathrm{O}$ 
caminho natural seria a criação de novos termos utilizando elementos próprios da língua indígena, o que não é possível na atual situação sociolinguística dos Xerente, dada a velocidade com que as mudanças (sociais e linguísticas) vêm acontecendo.

No exemplo (1), o tópico é o próprio ambiente urbano e os desafios da opção de viver nele. O exemplo retrata um pouco da visão de mundo Akwẽ. Depois de falar da saudade que consequentemente sentiria do sobrinho e também o inverso $\left(\mathrm{X}_{1}\right)$, o tio o aconselha sobre o mal que esse sentimento em demasia pode causar, de acordo com os objetivos pretendidos pelo jovem ao fazer tal opção, ou seja, alcançar um "sonho", seja ele qual for $\left(\mathrm{X}_{2}\right)$. Em seguida $\left(\mathrm{X}_{3}\right)$, fala dos desafios a serem enfrentados para alcançar o objetivo, tanto em relação ao próprio povo, quanto em relação aos não indígenas com quem provavelmente passaria a conviver.

O Akwẽ compara características negativas e alerta para realidades nocivas do ambiente urbano, tal como o consumo de drogas. Ao enxergar esse fato como quase inevitável, dá instruções ao sobrinho sobre como proceder nessas situações $\left(\mathrm{X}_{5}\right)$. Além disso, o tio dá, de forma evidente, o devido apoio e incentivo ao jovem $\left(\mathrm{X}_{2}, \mathrm{X}_{4} \mathrm{X}_{6}\right.$ e permeado por todo o trecho). No CS, o português é alternado com o xerente frequentemente em constituintes que refletem objetos, conceitos e ações comuns na cidade (“ligá”, em $\mathrm{X}_{5 \text { ) }}$ ou, ainda, mais especificamente no exemplo analisado, aos constituintes relacionados ao objetivo particular do jovem que viveria na cidade, tais como "futuro" $\left(\mathrm{X}_{2}\right)$, “sonho" $\left(\mathrm{X}_{2}, \mathrm{X}_{4}, \mathrm{X}_{6}\right)$, "estudo" $\left(\mathrm{X}_{2}\right)$ e "realizá" $\left(\mathrm{X}_{6}\right)$.

Soma-se a isso outras estratégias particulares do falante no evento. Por exemplo, o CS é utilizado para indicar a emoção do falante também através de frases de efeito como "então nada é impossível"; "pra que amanhã depois" $\left(\mathrm{X}_{4}\right)$; ou "i amanhã pra qui você pode mostra pa cada um" $\left(\mathrm{X}_{6}\right)$, comuns no português. $\mathrm{O}$ nome invejoso $\left(\mathrm{X}_{3}\right)$, que possui como equivalente na língua indígena o sintagma predicativo waike-di, é a escolha marcada para enfatizar o conceito no ato de fala específico, ou seja, o termo utilizado em português dá maior ênfase ao conteúdo que ele denota.

Seguem outros exemplos de eventos de fala com CS realizados por falantes diversos em contexto urbano:

(2) bolsa di família nẽ wat kba stokra kmã sapkarê. governo mã ku sĩ $(m)$ vendê rê kõdi.

'Bolsa Família eu nem me enganei, não quis. Não se vende para o governo'. 
(3) ta bûka, tê vendê (ko) wam nẽ tkrê kmã hrã ãwẽ “ó pamõi”, ka...

'Olha lá, está vendendo e está gritando muito "olha pamonha", assim'...

(4) ah, eu comprei essa mota pkê ĩnĩhdu, tahã nã ît kmã krui wa mãtô îkmã to.

'Ah, eu comprei essa moto porque é meu neto, quando mando fazer alguma coisa ele junta (faz)'.

Nos exemplos (2) a (4), o português é alternado com a língua indígena quando noções como comprar e vender são o tópico dos atos de fala. Muitos desses verbos, além de nomes e conectores da língua portuguesa, podem ser considerados como empréstimos no xerente, dada a frequência/amplitude de uso e as adaptações morfofonológicas que receberam para serem adequados à estrutura da língua indígena, algumas das características que os distinguem do code-switching. Observa-se, assim, o CS construído a partir de normas situacionais (GUMPERZ, 1982), cujo valor simbólico coincide com os contextos de produção.

Em doze de janeiro de 2014, na segunda ocasião da visita à Goiânia de um de nossos auxiliares de pesquisa, Maurício Srõne Xerente, presenciamos um fato que ajuda a explicar essa afirmação. Em janeiro acontece uma das etapas do curso de licenciatura intercultural na UFG. Alguns Xerente participam desse curso. Srõne pediu que eu o levasse ao local onde estavam hospedados seus parentes em Goiânia, para fazer uma visita. Ao chegarmos próximo ao local combinado, Maurício pediu o telefone para ligar para o seu primo. A ligação estava no modo 'viva voz'. Maurício falou com o primo em xerente, que inicialmente também lhe respondeu na língua indígena. Após alguns segundos de conversa, exatamente quando o primo começou a falar sobre o local onde estava na cidade, e que buscaria Srõne onde estávamos, ele começou a responder em português. No carro, além do pesquisador, havia um menino, curioso tal como uma criança de onze anos, perguntou ao Maurício porque ele perguntava na língua indígena e o primo respondia em português. Maurício respondeu prontamente: "é porque tá na cidade!". Além desse fator, acreditamos que o tópico também foi de força influente.

No fato narrado, como a intenção era de se encontrarem em local específico, na cidade, as referências e menções a conceitos físico-espaciais do espaço urbano podem ter tornado a comunicação em português mais funcional. Acreditamos ainda que Srõne hesitou em usar o português pelo fato do pesquisador 
estar próximo. A esta altura, devido ao seu grau de participação na pesquisa, ele já estava bastante consciente sobre a ocorrência do fenômeno e as prováveis motivações atuantes. Sempre quando comenta e observa as ocorrências de code-switching, Maurício se demonstra atento e preocupado em relação à frequência com que o português vem sendo utilizado - principalmente na cidade - que, segundo sua intuição, é cada vez maior.

\section{Discussão}

$\mathrm{O}$ uso de code-switching e empréstimos não representa em si um fator negativo à vitalidade das línguas. Tratam-se, na verdade, de fenômenos comuns a todas as línguas e, no caso do CS, especialmente utilizado por falantes bilíngues como estratégia discursiva com finalidades já amplamente abordadas pela literatura pertinente. Por outro lado, esses fenômenos merecem maior atenção em casos de contextos de contato (sociocultural e, consequentemente, linguístico) com configurações de assimetria política, econômica e, portanto, de relações de poder.

O problema, nesse sentido, não está na simples ocorrência dos fenômenos, mas na forma como eles se dão. Assim, mesmo algumas variáveis com maior resistência ao uso de code-switching, apontadas em Mesquita (2015), como idade mais avançada (+velhos) e baixa escolaridade (ou pessoas que não frequentaram a escola), parecem ceder às pressões do ambiente e tópicos relacionados ao contexto urbano. Durante todo o período que estivemos com os Xerente, o único evento (registrado em diário de campo) em que observamos dois idosos falando português entre si (o que, segundo os próprios Xerente, nunca acontece), deu-se justamente na cidade.

Em agosto de 2013, três idosos Xerente bebiam na praça central de Tocantínia. Dois deles, uma senhora e um senhor, estavam bastante exaltados e discutiam entre si enquanto o outro só observava. Sem se importar com a presença do pesquisador e outros não-indígenas próximos, trocaram ofensas, se empurraram e quase se agrediram. Discutiam sobre um equipamento agrícola que teria sido vendido sem o devido consentimento da comunidade. Usaram code-switching e, na maior parte do tempo, português. Isso representa uma quebra do conjunto de fatores situacionais relacionados às atitudes e expectativas dos falantes na relação entre eles, no qual a língua xerente é a escolha mais comum entre falantes indígenas, regra sociolinguística essa que é ainda mais forte entre os mais velhos.

Em geral, a língua xerente é a escolha não marcada para os falantes indígenas. Quando se questiona a um Xerente qual é a língua que ele/ela utiliza 
com outro Xerente, a resposta natural é "akwẽ mrmẽze" (língua xerente) ou simplesmente, "akwẽ" (MESQUITA, 2006).

Em casos como o supracitado (e também dos exemplos expostos na seção anterior), falar português entre si representa ainda um novo conjunto de expectativas no qual o ambiente urbano (e todo o universo que isso implica) exerce influência sobre as escolhas linguísticas dos falantes, levando-os então à utilização da língua majoritária. Na cidade, ambiente onde os conflitos diglóssicos são potencializados pela hegemonia da língua portuguesa, essa língua tem mais espaço para exercer as funções sociais operadas pelos interesses e pressões sofridas pelos Akwẽ naquele ambiente.

No entanto, o mesmo processo pode ser observado nas aldeias, à medida que elementos do ambiente urbano são levados para lá. Registramos, em um evento de discursos de lideranças na aldeia Salto, com a presença de autoridades não-indígenas e muitos não-indígenas, o cacique da aldeia se dirigindo aos demais caciques em português. $\mathrm{O}$ cacique faz um discurso em português para as autoridades e, na sequência, quando faz um apelo se dirigindo aos demais caciques Akwẽ, continua na mesma língua:

(5) intão, isso qui eu queria dizê pra vocêis, meu amigos caciques qui estão aqui, qui nós viemu briganu, sobre umas coisa que não tem futuro. vamo vê futuro qui somos nós, qui é a nossa saúde, vamu si reuní! vamu tê uma reunião! vamu a Brasília!

Na cidade, porém, há vários outros motivadores extralinguísticos que influenciam para um uso do code-switching ainda mais frequente. Conforme as análises, os participantes dos eventos, os tópicos potenciais, o ambiente muitas vezes hostil por motivo da condição marginalizada, as relações econômicas e as normas sociais em geral, estão entre eles. Conforme Myers-Scotton (1993), a escolha dos códigos é modificável, dinâmica e circunstancial. Então, além disso, é claro, deve-se considerar o grau como os indivíduos são influenciados por tudo isso, e como reagem através da escolha dos códigos.

A situação sociolinguística na cidade, neste sentido, é constituída pelas pressões que estão em atuação e pelo posicionamento dos indivíduos. Assim, conforme Fishman (1985) e Cáccamo (1987), o desejo de avanço ou progressão social que os indivíduos possam almejar funciona como incentivo para aquisição e utilização da língua dominante no âmbito urbano. Conforme os autores, isso se dá progressivamente até o ponto em que a transmissão da língua nativa para as gerações futuras é enfraquecida pelo aumento das pressões sociais. 
Ademais, algumas estratégias são especialmente utilizadas pelos Xerente em ambiente urbano, onde o maior contato com os não-indígenas é mais frequente. Uma vez que estes últimos não dominam a língua indígena, a cidade é o ambiente onde a língua xerente funciona como um código que garante o confidencialismo entre os Akwẽ. Os falantes atuam como atores racionais (MYERS-SCOTTON, 1998) que fazem escolhas linguísticas de acordo com suas intenções comunicativas em um contexto em que, em muitas situações, encontram-se minorizados ou marginalizadas.

Este trabalho não pretende esgotar as possibilidades de análise para entender a atual situação sociolinguística dos Xerente em Tocantínia. Outras possibilidades de leitura, tal como o desejo de se manterem em seus territórios tradicionais (uma vez que a cidade foi consolidada sobre um antigo aldeamento Xerente, como apontamos na perspectiva histórica) e os possíveis trânsitos (e conflitos) que isso pode ocasionar também são relevantes e poderão ser abordadas em oportunidades futuras.

Espera-se, com o presente trabalho, uma contribuição para o melhor entendimento das ocupações indígenas em território urbano, assim como das configurações do contato sociocultural a partir de uma visão sociolinguística. Assim, o trabalho fornece meios para a reflexão sobre a conscientização linguística e a elaboração de políticas públicas visando a autonomia cultural e linguística do povo Akwẽ-Xerente nos espaços que ocupam, incluindo aí o espaço urbano.

\section{Referências}

BRAGGIO, Silvia. L. B. Línguas indígenas brasileiras ameaçadas de extinção. Revista do Museu Antropológico. Goiânia, v. 5/6, p.9-54, 2001/2002.

Um Estudo Tipológico Sociolinguístico dos Xerente Akwe: Questões de Vitalização. In: AGUIAR, Ofir Bergmann de (Org.) Região, Nação, Identidade. Goiânia: AGEPEL: Instituto Centro-Brasileiro de Cultura, 2005a, p.165-183.

Revisitando a fonética/fonologia da língua Xerente Akwe: uma visão comparativa dos

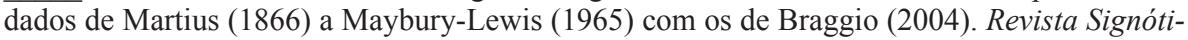
ca. Goiânia, v. 17, n. 2, 2005b, p. 251-273.

.. Reflexões sobre os empréstimos do tipo loanblend e direto na língua xerente akwén. Revista de Estudos da Linguagem, [S.1.] v. 18, n.1, jan/jun, p.87-100, 2010.

CÁCCAMO, Celso Álvares. Fala, bilinguismo, poder social. Agália: Revista da Associaçom Galega da Língua, n.10, p.127-150, 1987.

CALVET, Louis-Jean. As políticas linguísticas. São Paulo: Parábola Editorial: IPOL, 2007. 166p. 
FARIAS, Agenor José T. Fluxos Sociais Xerente - organização social e dinâmica entre as aldeias. 1990, 196f. Dissertação (Mestrado em Atropologia Social) - Curso de Pós-Graduação em Ciência Social, Universidade de São Paulo, São Paulo, 1990.

FERGUSON, Charles A. Diglossia. In: GIGLIOLI, Pier Paolo (Ed.). Language and social context: selected readings. Harmondsworth: Penguin Books, 1972 [1959], p.232-251. 234, 1991.

Epilogue: diglossia revisited. Southwest Journal of Linguistics, [S.1.] v. 10, n. 1, p.214-

FISHMAN, Joshua H. Bilingualism with and without diglossia; diglossia with and without bilingualism. Journal of Social Issues, [S.1.] v. 23, n. 2, p.29-38, 1967.

The rise and fall of the ethnic revival: perspectives on language and ethnicity. Berlin New York - Amsterdam: Mouton, 1985. 531p.

GIRALDIN, Odair; SILVA, Cleuber Alves da. Ligando Mundos: relação entre xerente e a sociedade circundante no século XIX. Boletim do Museu Paraense Emílio Goeldi. Belém, 2002.

GROSJEAN, François. Life With Two Languages: an Introduction to Bilingualism. Harvard University Press, 1982. 384p.

GUMPERZ, John J. (Ed.). Discourse strategies. Cambridge, UK: Cambridge University Press, 1982. $237 \mathrm{p}$

. Introduction to part IV. In: GUMPERZ, John. J.; LEVINSON, Stephen C. (Ed.). Rethinking linguistic relativity. Cambridge: Cambridge University Press, 1996, p.359-373.

HAMEL, Rainer Enrique. La política del lenguaje y el conflicto interétnico - Problemas de investigación sociolinguística. In: ORLANDI, Eni (Ed.). Política Linguística na América Latina. Campinas: Pontes, 1988, p.41-74.

HYMES, Dell. Toward ethnographies of communication: the analysis of communicative events. In: GIGLIOLI, Pier Paolo. (Ed.). Language and social context. Harmondsworth: Penguin Books, 1972 [1964], p.21-43.

. Foundations in sociolinguistics: an ethnographic approach. 9a ed. Philadelphia: University of Pennsylvania Press, 1974.

. Models of the interaction of language and social life. In: GUMPERZ, John J.; HYMES, Dell (Ed.). Directions in Sociolinguistics: The Ethnography of Communication. New York: Holt, Rinehart, Winston, 1986, p.35-71.

IBGE, Instituto Brasileiro de Geografia e Estatística. Censo demográfico 2010. Disponível em: $<$ http://indigenas.ibge.gov.br/>. Acesso em 09 jan. 2015.

KRIEGER, Wanda Braidotti; KRIEGER, Guenther Carlos. Dicionário escolar: Xerente-Português-Xerente. Rio de Janeiro: Junta das Missões Nacionais da Convenção Batista Brasileira, 1994.

MESQUITA, Rodrigo. Migração e usos/atitudes da língua xerente akwẽ na cidade: um estudo sociolinguístico dos xerente em Tocantínia. 2006, 45f. Monografia (Bacharelado em Letras e Linguística). Universidade Federal de Goiás, Goiânia, 2006. 
.. Empréstimos do Português em Xerente Akwẽ. 2009, n. 144f. Dissertação (Mestrado em Letras e Linguística). Universidade Federal de Goiás, Goiânia, 2009.

Code-switching em Akwẽ-Xerente/Português. Tese (Doutorado em Letras e Linguística). Universidade Federal de Goiás, Goiânia, 2015.

MYERS-SCOTTON, Carol. Social Motivations for Codeswitching: Evidence from Africa. New York: Oxford University Press, 1993. 189p.

. A Theoretical Introduction to the Markedness Model. In: MYERS-SCOTTON, Carol (Ed.). Codes and Consequences: Choosing Linguistic Varieties. New York: Oxford University Press, 1998, p.18-38.

RIBEIRO, Darcy. Os índios e a Civilização: a integração das populações indígenas no Brasil moderno. $5^{\mathrm{a}}$ ed. Petrópolis: Vozes, 1986. 559p.

ROMAINE, Suzanne. Bilingualism. 2a Ed. Oxford: Blackwell, 1995. 384p.

ROSADO, Rosa Maris; FAGUNDES, Luiz Fernando Caldas (Orgs). Presença indígena na cidade: reflexões, ações e políticas. Núcleo de Políticas para Povos Indígenas. Porto Alegre:

Gráfica Hartmann, 2013.

Submissão em: 10/02/2015

Aceite em: 02/09/2015

Rodrigo Mesquita possui mestrado e doutorado em Letras e Linguística pela Universidade Federal de Goiás. É Professor Adjunto na Universidade Federal de Roraima - Campus Paricarana. Endereço para correspondência: Campus Paricarana Av. Capitão Ene Garcez, 2413, Bloco I - CCLA - Bairro Aeroporto. CEP 69304-000, Boa Vista - RR.

E-mail: rodrigomesquitago@hotmail.com 